REPRINTED FROM ANNALS OF OTOLOGY, RHINOLOGY \& LARYNGOLOGY, MARCH-APRIL 1984
Volume 93

COPYRIGHT 1984, ANNALS PUBLISHING COMPANY

\title{
COMPARISON OF TWO COCHLEAR IMPLANT SPEECH-PROCESSING STRATEGIES
}

\author{
Graeme M. Clatk, PhD, FRAcS \\ YIT CHOW TONG, PHD RICHARD C. DOWEll, DiP AUd
}

East Melbourne, Australia

Speech processors extracting either the fundamental frequency (F0) alone, or the fundamental frequency combined with second formant information (F0-F2), have been evaluated on a totally deaf patient using a multiple-channel cochlear implant. A closed set test using 16 spondees and a modified rhyme test showed that for electrical stimulation alone the F0-F2 speech processor was significantly better than the F0 processor. The open set tests using phonetically balanced words and Central lnstitute for the Deaf everyday sentences showed that for electrical stimulation alone and electrical stimulation combined with lipreading, the results with the F0-F2 speech processor were all significantly better than with the F0 processor. Information transmission for consonant speech features was also better when using the F0-F2 processor.

\section{INTRODUCTION}

Electrical stimulation of residual auditory nerve fibers can help postlingually deaf patients communicate, ${ }^{1.9}$ and it also offers hope of assisting the prelingually deaf. For further progress in the field it is important to evaluate the various speech-processing and stimulus systems available, and to design and develop others.

For this reason it was considered of value to compare the effects of two speech-processing strategies on our first postlingually deaf cochlear implant patient. On Aug 1, 1978 this patient had a receiverstimulator implanted in the mastoid bone, and a 10-channel multiple-electrode array inserted through the round window and along the scala tympani of the basal turn of the cochlea.

Following a series of psychophysical tests, a speech-processing strategy was developed where the voicing frequency of speech (F0) and its energy (A0) were extracted using a $400-\mathrm{Hz}$ low-pass filter, and an energy threshold detector of $\mathrm{A} 0$ was used to determine whether voicing was present or not. In the presence of voicing the pulse rate on electrodes was made proportional to F0. If voicing was absent a constant low pulse rate was used since it produced a sensation described as "rough" which was similar to a "noise" sensation previously experienced by the patients when they had hearing. In addition, the frequency of the dominant spectral peak in the midfrequency range, called the second formant frequency (F2), and the energy associated with this peak (A2) were estimated from the output of a 750 to $4,000-\mathrm{Hz}$ band-pass filter. For a given F2 estimate, an electrode was selected from a predetermined F2-to-electrode transformation map, which had been constructed by ranking the electrodes from dullest to sharpest, and assigning frequency subbands to these electrodes in an order from lowest to highest. Similarly, the current level was determined on the basis of an A2-to-current-level map. The speech parameters were determined every 10 $\mathrm{ms}$ and only one electrode was activated within a 10-ms time frame. ${ }^{10}$

Since May 1980 the patient has been continuously using a wearable speech processor in his home environment. During this time the processor extracted and presented him with both F0 and F2 frequencies. In March 1982 a study was undertaken to compare the speech information perceived when extracting either the $\mathrm{F} 0$ alone, or both the F0 and F2. To be sure the patient was receiving maximal information in the F0 mode, equal exposure to an F0 speech processor would have been desirable. It was difficult to get the patient to accept this training routine as he had experienced better speech perception with a F0-F2 processor right from the outset when informal comparisons were made with an F0 processor. It was therefore necessary to assume that in the combined F0-F2 mode, the amount of information obtained through the F0 channel was optimal. An audiological evaluation of the two processors using closed sets of 16-spondee words, open sets of phonetically balanced words, and open sets of Central Institute for the Deaf (CID) sentences showed better results for the F0-F2 than the F0 processor. ${ }^{11}$

The present study has been undertaken to extend the audiological assessment of these two speechprocessing strategies, and to make a statistical comparison of the results. Since nonsense syllables have

From the Department of Otolaryngology, University of Melbourne, and The Royal Victorian Eye and Ear Hospital, East Melbourne, Victoria, Australia. This study was funded by the National Health and Medical Research Council of Australia, and the Department of Science and Technology of the Australian government.

REPRINTS - Graeme M. Clark, PhD, FRACS, Department of Otolaryngology, University of Melbourne, The Royal Victorian Eye and Ear Hospital,

East Melbourne, Vic 3002, Australia. 
been of value in providing information about the speech features perceived with electrical stimulation, ${ }^{10.12}$ they have also been used in the present study to compare the two speech-processing strategies.

\section{METHODS}

Over a period of three days in March 1982, the patient was tested with both the $\mathrm{F} 0$ and the $\mathrm{F} 0-\mathrm{F} 2$ speech processors for the test conditions electrical stimulation plus lipreading (EL) and electrical stimulation alone (EA). During this period lipreading alone (LA) scores were obtained for the F0 processor test series, but, due to a shortage in list material, the LA scores for the F0-F2 processor were obtained from a test series performed some months previously. The comparison was made using closed sets of 16-spondee (16-SP) words, ${ }^{13}$ closed sets of modified rhyme test (MRT) words, ${ }^{14}$ open sets of Arthur Boothroyd (AB) words, ${ }^{15}$ the word intelligibility by picture identification (WIPI) ${ }^{16}$ lists as open sets of words, and open sets of CID everyday sentences. ${ }^{17}$ It has been shown that for the $\mathrm{AB}$ words ${ }^{18}$ and the CID sentences ${ }^{19}$ certain lists should not be used to ensure list equivalence. These requirements have been met in this study so that any differences in the results were not due to variations in test difficulty. Furthermore, it has been shown that the four lists of WIPI words are highly equivalent. ${ }^{10}$ The word and sentence tests were all adapted for Australian conditions ${ }^{19}$ and presented by a male audiologist with an Australian accent and experience in monitoring the intensity of his own voice. The speech processor intensity control was set at the most comfortable listening levels for speech. Previously, the current levels between threshold and the most comfortable levels for each electrode had been programmed into the erasableprogrammable read-only memory (EPROM) of the processor. The patient was placed in a sound-attenuated room with the tester outside. Lipreading evaluations were performed using a video camera to display the tester's face on a monitor in the room. The testing of the F0 speech processor was performed on March 15 and the F0-F2 processor on March 19 and 22. During this period there was no change in the thresholds at the different electrodes. The subject had previous experience with the tests in May 1980, May 1981, and October 1981.

The order of presentation of the test conditions was EL, EA, and LA. This means that any practice effect tended to reduce the expected difference between the scores for LA and EL. It should also be noted that the better results obtained for the F0-F2 processor in the EL condition could lead to a greater learning effect and a carryover to a better performance for the EA condition. This could, in turn, result in improved scores for EA with the F0-F2 compared to the F0 speech processor.

With the 16-SP word test each word was presented randomly five times until a total of 80 were given. For the MRT, 50 ensembles of six rhyming words were used for each evaluation, and the patient was asked to identify the test word selected from each ensemble. He was not informed about the correctness of his response. A computer program randomized the order of the 50 en sembles of rhyming words; the order of the six words within each ensemble was printed on the test form as was the order of the test word from each ensemble. In this way the material could be used repeatedly, without learning or a response bias affecting the results.

There were $15 \mathrm{AB}$ word lists. Each list contained ten words and 30 phonemes, and the phoneme composition of the lists was standardized. Two practice words were presented before each list. For each condition two lists of ten words (a total of 20 words and 60 phonemes) were presented, except for lipreading alone, when one list was given for each speech processor. The WIPI words were contained in four test lists, and in each list there were 25 monosyllabic words and 80 phonemes. With children these are usually used in a closed set, but for the speech-processing evaluation the words were presented as an open set and the patient was not given any clues about their identity. For each condition 25 words and 80 phonemes were presented. With the CID sentences there were ten lists; each list contained ten sentences and 50 score words. For each condition ten sentences containing 50 score words were presented.

The statistical significance of the differences in the results for the F0 and F0-F2 speech processors was evaluated by modeling the scores as a binomial variable. ${ }^{20} \mathrm{An}$ arc-sine transformation was first performed on the scores. The variance of a difference between transformed scores was then calculated, and the probability of an observed difference occurring by chance estimated using a Z-table. In this way critical differences were estimated for each of the pairs of scores obtained.

Finally, the identification of nonsense syllables was investigated using the 12 consonants $/ \mathrm{b} /, / \mathrm{p} /, / \mathrm{m} /, / \mathrm{v} /, / \mathrm{f} /, / \mathrm{d} /, / \mathrm{t} /, / \mathrm{n} /$, $/ z /, / \mathrm{s} /, / \mathrm{g} /$, and $/ \mathrm{k} /$ in a vowel-consonant-vowel context with the vowel $/ \mathrm{a} /$. This was undertaken for the $\mathrm{F} 0$ speech processor so that the results could be compared with those obtained previously for the F0-F2 processor. ${ }^{2}$ The test was performed in a similar manner, ${ }^{12}$ and the closed sets of randomized syllables were presented for the conditions EL, EA, and LA. There were ten presentations of each consonant for each condition, or a total of 120 per condition. For the F0-F2 processor evaluation there were 240 presentations per condition. The information transmission for the speech features voicing, nasality, affrication, duration, and place, was also calculated.

Percentage information transmission was defined by Miller and Nicely" as the ratio of the number of bits of information detected by the patient to the information available in the stimulus, expressed as a percentage, or ${ }^{T}$ Percent ${ }^{[x: y]}=T(x: y) / H(x) \times 100$, where $T(x: y)$ is the information transmission from $x$ (stimuli) to $y$ (responses) in bits per stimulus, and $H(x)$ is the information available in the stimuli in bits per stimulus.

For example, if, in the present study, there were an equal number of voiced and unvoiced consonants, one bit of information would be present in the stimuli presented. One bit of information being transmitted is a choice between two alternatives. If all the voiced consonants were correctly distinguished from the unvoiced consonants, one bit of information would have been transmitted, and the information transmission would be $100 \%$. If the patient were to guess the result on the basis of prior knowledge, he/she would at best be right $50 \%$ of the time, and in this case $0 \%$ information would have been transmitted. Consequently, information transmission is a more meaningful way of assessing a patient's response than recording a percentage-correct score. In the present study information transmission was obtained from the confusion matrices using each cell to calculate the bits of information transmitted from the stimulus to the response, and the bits of information available in the stimulus. The results were obtained from both 120 observations/matrix and 240 observations/matrix, which are smaller than previous studies. ${ }^{21-23}$ This would tend to be an overestimate of the information transmission statistics. As twice as many observations were made for the F0-F2 compared to the $\mathrm{F} 0$ processor, the $\mathrm{F} 0$ results could also be an overestimate. The application of the information-transmission analysis to our studies is described in more detail by Dowell et al. ${ }^{12}$

\section{RESULTS}

The results of the 16-SP word, MRT word, AB word, WIPI word, and CID sentence tests for the F0 and F0-F2 speech processors are shown in Table 1 . It can be seen that, for the closed set 16-SP words and EA condition, the F0 processor gave a $28 \%$ score. This increased to a score of $100 \%$ for the F0-F2 processor, and was statistically significant at the $0.05 \%$ probability level. With closed sets of MRT words the scores for EA were $24 \%$ for the F0 processor and $50 \%$ for the F0-F2 processor; this difference was significant. For the EL condition the improvement with the $\mathrm{F} 0-\mathrm{F} 2$ processor was not sig- 
TABLE 1. COMPARISON OF F0 AND F0-F2 SPEECH PROCESSORS

\begin{tabular}{|c|c|c|c|c|c|}
\hline Test & Condition & $\begin{array}{c}\text { Fo Speech } \\
\text { Processor (\%) }\end{array}$ & $\begin{array}{c}\text { Upper and Lower } \\
5 \% \text { Critical } \\
\text { Differences } * \%)\end{array}$ & $\begin{array}{l}\text { F0-F2 Speech } \\
\text { Processor (\%) }\end{array}$ & $\begin{array}{l}\text { Upper and Lower } \\
5 \% \text { Critical } \\
\text { Differences }(\%)\end{array}$ \\
\hline $16-\mathrm{SP}$ words & EA & 28 & $+14,-14$ & $100 \dagger$ & $\mathrm{NA},-5$ \\
\hline MRT words & $\begin{array}{l}\text { EA } \\
\text { LA } \\
\text { EL }\end{array}$ & $\begin{array}{l}24 \\
62 \\
76\end{array}$ & $\begin{array}{l}+20,-16 \\
+20,-20 \\
+16,-20\end{array}$ & $\begin{array}{l}50 \dagger \\
58 \\
84\end{array}$ & $\begin{array}{l}+20,-20 \\
+20,-20 \\
+12,-18\end{array}$ \\
\hline $\mathrm{AB}$ words & $\begin{array}{l}\text { EA } \\
\text { LA } \\
\text { EL }\end{array}$ & $\begin{array}{r}0 \\
10 \\
20\end{array}$ & $\begin{array}{l}+15, \quad \text { NA } \\
+30, \quad \text { NA } \\
+30,-20\end{array}$ & $\begin{array}{l}25 \dagger \\
20 \\
50 \dagger\end{array}$ & $\begin{array}{l}+30,-25 \\
+30,-20 \\
+30,-30\end{array}$ \\
\hline $\mathrm{AB}$ phonemes & $\begin{array}{l}\text { EA } \\
\text { LA } \\
\text { EL }\end{array}$ & $\begin{array}{l}10 \\
53 \\
53\end{array}$ & $\begin{array}{l}+14,-10 \\
+18,-18 \\
+18,-18\end{array}$ & $\begin{array}{l}42 \dagger \\
53 \\
72 \dagger\end{array}$ & $\begin{array}{l}+18,-18 \\
+18,-18 \\
+15,-18\end{array}$ \\
\hline WIPI words & EA & 0 & $+12, \quad \mathrm{NA}$ & $28 \dagger$ & $+28,-24$ \\
\hline WIPI phonemes & EA & 8 & $+12,-8$ & $50 \dagger$ & $+16,-16$ \\
\hline ClD sentences & $\begin{array}{l}\text { EA } \\
\text { LA } \\
\text { EL }\end{array}$ & $\begin{array}{r}0 \\
42 \\
60\end{array}$ & $\begin{array}{l}+8, \quad \text { NA } \\
+20,-20 \\
+20,-20\end{array}$ & $\begin{array}{l}22 \dagger \\
36 \\
98 \dagger\end{array}$ & $\begin{array}{r}+20,-16 \\
+20,-18 \\
\text { NA, }-12\end{array}$ \\
\hline
\end{tabular}

†Significantly different from F0 speech processor score at $5 \%$ level (Thornton and Raffin ${ }^{20}$ ).

nificant. With the open sets of $\mathrm{AB}$ words, scored on the basis of words identified, the patient obtained a significant improvement when using the F0-F2 processor compared to the F0 processor. For EA the score increased from $0 \%$ to $25 \%$, and for EL from $20 \%$ to $50 \%$. When the test was scored phonemically, significant improvements also occurred. The EA result went from $10 \%$ to $42 \%$, and the EL result went from $53 \%$ to $72 \%$. A highly significant improvement for $\mathrm{F} 0-\mathrm{F} 2$ versus $\mathrm{F} 0$ processing was also seen with the open set of WIPI words scored both on the words and phonemes identified. For the EA condition the word score increased from $0 \%$ to $28 \%$, and the phoneme score from $8 \%$ to $50 \%$. Finally, the results for the CID everyday sentences showed significantly improved performances for the F0-F2 versus the F0 processor for both the EA and EL conditions. The score increased from $0 \%$ to $22 \%$ for EA, and from $60 \%$ to $98 \%$ for EL.

Table 2 shows the information transmission obtained with both the F0 and F0-F2 processors for the speech features: voicing, nasality, affrication, duration, and place, and the consonants $/ \mathrm{b} /, / \mathrm{p} /$, $/ \mathrm{m} /, / \mathbf{v} /, / \mathbf{f} /, / \mathbf{d} /, / \mathbf{t} /, / \mathbf{n} /, / \mathbf{z} /, / \mathbf{s} /, / \mathrm{g} /$ and $/ \mathbf{k} /$. With the EA condition the percentage information transmission was essentially the same for both processors for the voicing distinction $(26 \% \quad \mathrm{~F} 0 ; 25 \%$ $\mathrm{F} 0-\mathrm{F} 2$ ). On the other hand, for all other speech features, better scores were obtained for the F0-F2 processor compared to the $\mathrm{F} 0$ processor. The overall transmission also increased from $35 \%$ for the F0 processor to $42 \%$ for the $\mathrm{F} 0-\mathrm{F} 2$ processor. The speech feature scores were all higher for the F0-F2 processor compared to the F0 processor for the EL condition. Overall transmission also increased from $63 \%$ for the F0 processor to $75 \%$ for the F0-F2 processor.

\section{DISCUSSION}

The results of the evaluation of the two speech- processing strategies showed that for EA the F0-F2 processor was always significantly better than the F0 processor. This finding is consistent with our previous psychophysical results, where spectral information could be perceived by our multiplechannel cochlear implant patients on the basis of the site of electrode stimulation, ${ }^{24}$ and where site and rate of stimulation are perceived as two separate percepts. ${ }^{25-27}$ Consequently, the F0-F2 speechprocessing strategy, where voicing is represented as rate and the second formant as site of stimulation, conveys more information than the F0 processor, where only voicing is transmitted.

This was confirmed by our consonant-confusion study where the results showed that voicing was transmitted equally well by both the F0 and F0-F2 speech processors, but nasality, affrication, duration and place were all better transmitted by the F0-F2 processor. Fundamental frequency alone is not the only cue for voicing. Voice onset time and first formant (F1) transition are also important. Further improvements in speech processing should be possible if these cues are also maximized. The better performance for nasality with the $\mathrm{F} 0$-F2 processor was probably due to the fact that a rising or falling F2 is important for the perception of these phonemes $^{21.28}$ and is conveyed by the F0-F2 pro-

TABLE 2. COMPARISON OF CONSONANT SPEECH FEATURE INFORMATION TRANSMISSION IN F0 AND F0-F2 SPEECH PROCESSORS*

\begin{tabular}{|c|c|c|c|c|c|c|}
\hline \multirow[b]{2}{*}{ Features } & \multicolumn{2}{|c|}{$E A$} & \multicolumn{2}{|c|}{$L A$} & \multicolumn{2}{|c|}{$E L$} \\
\hline & $\begin{array}{l}F 0 \\
(\%)\end{array}$ & $\begin{array}{c}F 0-F 2 \\
(\%)\end{array}$ & $\begin{array}{c}F 0 \\
(\%) \\
\end{array}$ & $\begin{array}{c}F 0-F 2 \\
(\%)\end{array}$ & $\begin{array}{c}F 0 \\
(\%)\end{array}$ & $\begin{array}{c}F 0-F 2 \\
(\%)\end{array}$ \\
\hline Voicing & 26 & 25 & 0 & 0 & 28 & 46 \\
\hline Nasality & 5 & 10 & 3 & 5 & 16 & 43 \\
\hline Affrication & 11 & 28 & 27 & 37 & 52 & 100 \\
\hline Duration & 10 & 80 & 11 & 22 & 33 & 100 \\
\hline Place & 4 & 19 & 70 & 69 & 70 & 80 \\
\hline Overall & 35 & 42 & 54 & 47 & 63 & 75 \\
\hline
\end{tabular}

${ }^{*}$ Consonants tested were b, p, m, v, f, d, t, n, z, s, g, and k. 
cessor. With affrication, concentrations of frequency energy in the $\mathrm{F} 2$ region $^{29}$ are the important cues, and this would explain the better performance of the F0-F2 processor. Furthermore, for fricatives, the duration of the burst of noise, the closure interval, and the duration of the associated vowels also help to distinguish them from plosives and from each other. The improved performance with the F0-F2 processor for the duration feature is interesting. Both processors should convey timing information equally well. The important cue, however, is mostly timing in relation to the F2 and this would, therefore, explain the better performance with the F0-F2 processor. The most significant cue for place is the $\mathrm{F} 2$ transition $^{21,30}$ and, since this was transmitted by the F0-F2 processor, this would explain the better results. Finally, as F1 information can also be useful in the perception of consonants and vowels, it is to be expected that improvements will result if speech processors transmit Fl as well as F0 and F2 information. Psychophysical studies on our first patient have, in fact, shown that this is possible with multichannel stimulation. ${ }^{31}$

When electrical stimulation was combined with lipreading, the scores obtained with the F0-F2 processor were significantly better for all tests except the MRT word lists, where the improvement from $76 \%$ to $84 \%$ was not significant. In this case, the relatively high score obtained with $\mathrm{F} 0$ suggests that the test is not sensitive. The significantly better results of the F0-F2 processor in the combined EL condition for all the $A B$ word, WIPI word, and
CID sentence tests are a measure of differences between the processors for normal discourse.

The better performance of the F0-F2 compared to the F0 speech processor when used in combination with lipreading was also seen when consonant speech-feature information transmission was measured. As shown in Table 2, information transmission was better for all speech features using the F0-F2 processor. Improvements obtained for nasality, affrication, and duration may not be as great as those recorded, as the F0-F2 processor also showed better scores for these features for LA. The scores for LA in the F0-F2 evaluations were obtained some months before those with the F0 processor, and minor differences in the lighting conditions and the small numbers of contrasting speech features in the test could account for the discrepancies. There were, however, a greater number of contrasting features in the test for voicing and place of articulation, and the results are therefore more reliable. They indicate that for place of articulation, the F2 information supplemented the lipreading cues and improved speech comprehension. The results obtained with voicing are more difficult to explain. They are, however, consistent with a previous study using the F0-F2 processor where the voicing results for EL were also better than EA. ${ }^{12}$ This is probably due to the test design where the voicing score also depends on the recognition of other features. For example, in detecting voicing in the above set of consonants, nasality cues can also be used.

\section{REFERENCES}

1. House WF, Berliner K, Crary W, et al. Cochlear implants. Ann Otol Rhinol Laryngol 1976; 85:(suppl 27).

2. Bilger RC, Black FO, Hopkinson NT, et al. Evaluation of subjects presently fitted with implanted auditory prostheses. Ann Otol Rhinol Laryngol 1977; 86:(suppl 38).

3. Eddington DK, Dobelle WH, Brackmann DE, Mladejovsky MG, Parkin JL. Auditory prosthesis research with multiple channel intracochlear stimulation in man. Ann Otol Rhinol Laryngol 1978; 87:(suppl 53).

4. Simmons FB, Mathews RG, Walker MG, White RL. A functioning multi-channel auditory nerve stimulator. Acta Otolaryngol (Stockh) 1979; 87:170-5.

5. Tong YC, Black RC, Clark GM, et al. A preliminary report on a multiple-channel cochlear implant operation. J Laryngol Otol 1979; 93:679-95.

6. Fourcin AJ, Rosen SM, Moore BCJ, et al. External electrical stimulation of the cochlea: clinical, psychophysical, speechperceptual and histological findings. Br J Audiol 1979; 13:85-107.

7. Chouard $\mathrm{CH}$. The surgical rehabilitation of total deafness with the multichannel cochlear implant: indications and results. Audiology 1980; 19:137-45.

8. Burian K, Hochmair E, Hochmair-Desoyer I, Lessel MR. Electrical stimulation with multichannel electrodes in deaf patients. Audiology 1980; 19:128-36.

9. Michelson RP, Schindler RA. Multichannel cochlear implant: preliminary results in man. Laryngoscope 1981; 91:38-42.

10. Clark GM, Tong YC, Martin LF, et al. A multiple-channel cochlear implant: an evaluation using nonsense syllables. Ann Otol Rhinol Laryngol 1981; 90:227-30.

11. Clark GM, Tong YC, Dowell RC. Clinical results with a multiple-channel pseudo-bipolar system. Ann NY Acad Sci 1982; 405:370-6.

12. Dowell RC, Martin LFA, Tong YC, Clark GM, Seligman PM, Patrick JF. A twelve consonant confusion study on a multiple-channel cochlear implant patient. J Speech Hear Res 1982; 25:509-16.

13. Hirsh IJ, Davis H, Silverman SR, Reynolds EE, Benson RW. Development of materials for speech audiometry. J Speech Hear Disord 1952; 17:321-37.

14. House AS, Williams CE, Hecker MHL, Kryter KD. Articulation-testing methods: consonantal differentiation with a closed-response set. J Acoust Soc Am 1965: 37:158-67.

15. Boothroyd A. Developments in speech audiometry. Sound $1968 ; 2: 3-10$.

16. Ross M, Lerman J. A picture identification test for hearing impaired children. J Speech Hear Res 1970; 13:44-53.

17. Davis H, Silverman SR. Hearing and deafness. New York: Holt, Rinehart and Winston, 3rd ed, 1970, 492-5.

18. Markides A. Speech discrimination functions for normalhearing subjects with AB isophonemic word lists. Scand Audiol 1978: 7:239-45.

19. Tonisson B. National Acoustic Laboratories' standardization of CID everyday sentence lists. Internal report, Natl Acoustic Laboratories, Brisbane, 1-12. 
20. Thornton AR, Raffin MJM. Speech-discrimination scores modelled as a binomial variable. J Speech Hear Res 1978; 21: 507-18.

21. Miller GA, Nicely PE. An analysis of perceptual confusions among some English consonants. J Acoust Soc Am 1955; 27: 338-52.

22. Singh S, Black JW. Study of twenty-six intervocalic consonants as spoken and recognized by four language groups. J Acoust Soc Am 1966; 39:372-87.

23. Wang MD, Bilger RC. Consonant confusions in noise: a study of perceptual features. J Acoust Soc Am 1973; 54:1248-66.

24. Tong YC, Miller JB, Clark GM, Martin LF, Busby PA, Patrick JF. Psychophysical and speech perception studies on two multiple channel cochlear implant patients. J Laryngol Otol 1980; 94:1241-56.

25. Tong YC, Clark GM, Blamey PJ, Busby PA, Dowell RC. Psychophysical studies for two multiple-channel cochlear implant patients. J Acoust Soc Am 1982; 71:153-60.

26. Tong YC, Blamey PJ, Dowell RC, Clark GM. The effects of electrode position and stimulus period on the hearing sensations in a multiple-channel cochlear implant patient. J Acoust Soc Am 1981; (suppl 1):70.

27. Tong YC, Clark GM. Percepts from scala tympanic stimulation. Ann NY Acad Sci 1982; 405:264-7.

28. Fujimura O. Analysis of nasal consonants. J Acoust Soc Am $1962 ; 34: 1865-75$

29. Heinz JM, Stevens KN. On the properties of voiceless fricative consonants. J. Acoust Soc Am 1961; 33:589-96.

30. Cooper FS, Delattre PC, Liberman AN, Borst JM, Gerstman LJ. Some experiments on the perception of synthetic speech sounds. J Acoust Soc Am 1952; 24:597-606.

31. Tong YC, Dowell RC, Blamey PJ, Clark GM. Two-component hearing sensations produced by two electrode stimulation in the cochlea of a totally deaf patient. Science 1983; 219:993-4. 


\section{University Library}

\section{- M M I E R R V A gateway to Melbourne's research publications}

Minerva Access is the Institutional Repository of The University of Melbourne

Author/s:

Clark, Graeme M.;Tong, Yit Chow;Dowell, Richard C.

Title:

Comparison of two cochlear implant speech-processing strategies

Date:

1984

Citation:

Clark, G. M., Tong, Y. C., \& Dowell, R. C. (1984). Comparison of two cochlear implant speech-processing strategies. Annals of Otology, Rhinology and Laryngology, 93(2), 127-131.

Persistent Link:

http://hdl.handle.net/11343/27200 